
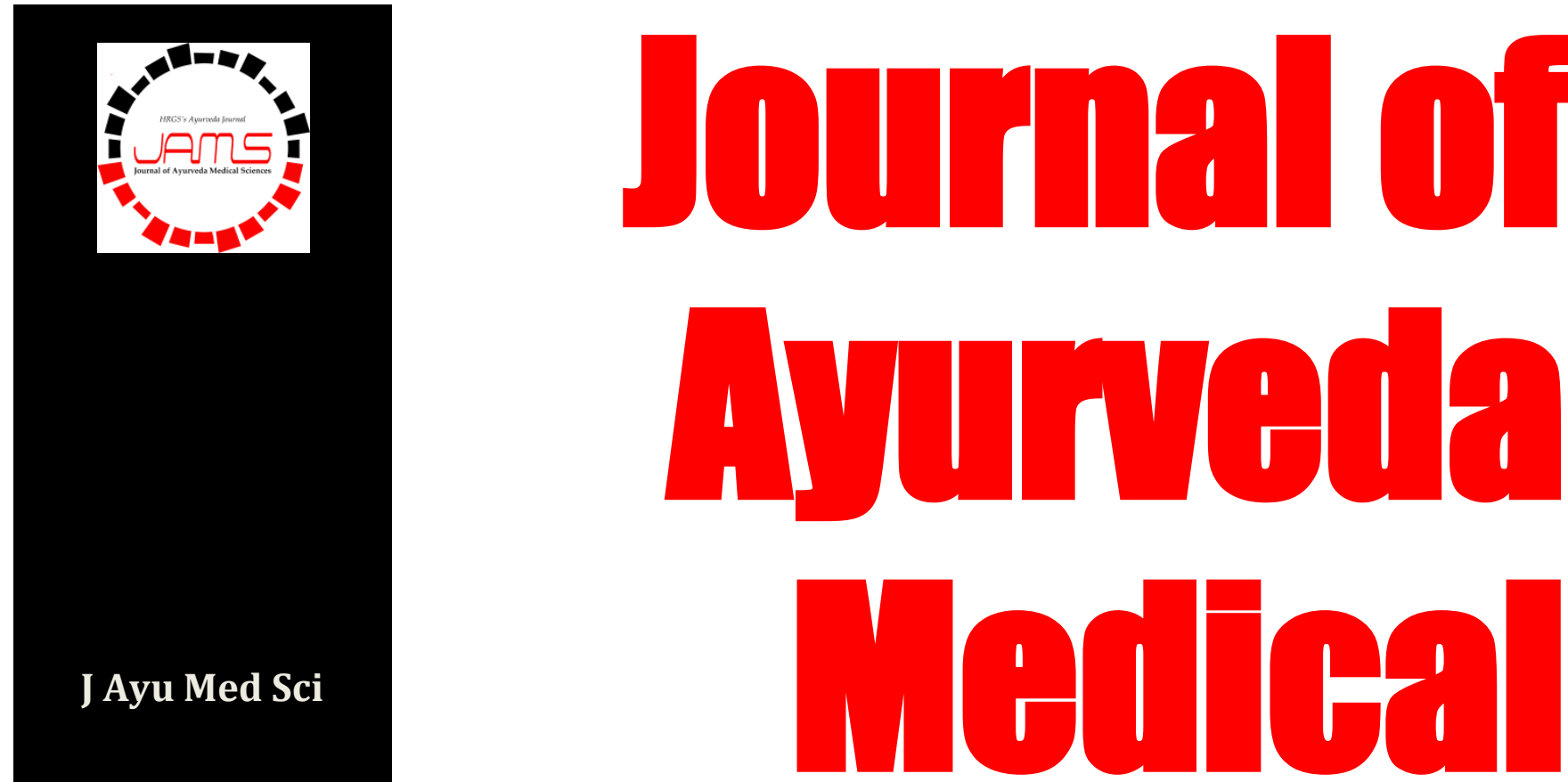

Quarterly Journal for

Rapid Publication

of Researches

in Ayurveda

and Other Traditional

Medicines

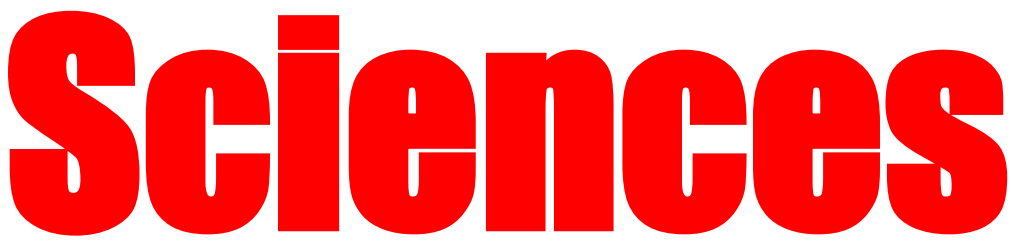

ISSN 2456-4990

www.jayumedsci.com

\title{
Macro-microscopic Differentiation of Guduchi Satva Samples Collected from Market
}

Guduchi satva is frequently used drug among Ayurvedic physicians for conditions such as Jvara (fever), Daha (burning sensation) and other Pitta predominant conditions. One laboratory sample of Guduchi satva was prepared by following classical method and four market samples were collected from different parts of country and efforts have been made to check organoleptic and microscopic characterization of the samples. The work has shown variations in randomly selected samples which may be due to collection of raw material from different seasonal and climatic conditions, differences in adapted method of preparation etc. 


\section{Macro-microscopic Differentiation of Guduchi Satva Samples Collected from the Market}

Paritosh Jha*, 'Sonam Bhinde, ${ }^{2}$ Harisha Channappa Rudrappa, Galib Ruknuddin, Pradeep Kumar Prajapati

All India Institute of Ayurveda, Sarita Vihar, New Delhi 110076. ' ${ }^{1}$ Bhargava Ayurveda College, Dehemi, Anand, Gujarat 388560. ${ }^{2}$ Pharmacognosy laboratory, IPGT \& RA, Gujarat Ayurved University, Jamnagar, Gujarat 361008 , India.

\begin{abstract}
Background: Guduchi Satva is frequently utilized drug among Ayurvedic physicians for conditions such as Jvara (fever), Daha (burning sensation) and other Pitta predominant conditions. Because of its numerous medicinal attributes, many pharmaceutical companies are manufacturing this formulation. This article is intended to check the difference in organoleptic and microscopic features of Guduchi Satva being sold in the market. One sample was prepared in the laboratory, while, the other samples were collected from the market. Methods: Five samples of Guduchi Satva were collected and organoleptic-microscopic features were recorded as per pharamcopoeial procedures. Results: More or less variation in Guduchi Satva samples was found. The reason could be difference in drug collecting area, season and using different references of preparation method. Conclusion: A consensus by all pharmaceutical companies for the use of identical classical reference in formula preparations by preparing monographs in AFI and API could solve the issue of differences from sample to sample. This article quest for the probable reason of variation and its solution.
\end{abstract}

KEYWORDS Guduchi Satva, Microscopy, Organoleptic examination, Quality control, Standardisation.

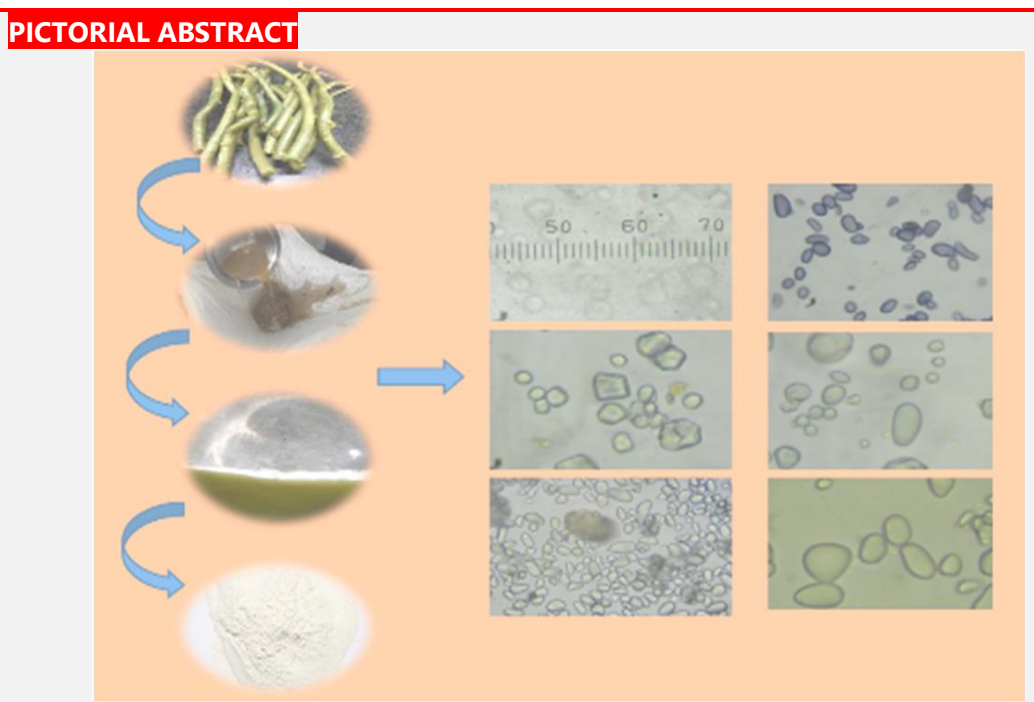

ARTICLE HISTORY Received08.04.2019 Accepted 19.04.2019

CORRESPONDENCE Paritosh Jha, Department of Rasa Shastra \& Bhaishajya Kalpana, All India Institute of Ayurveda, Sarita Vihar, Mathura Road, New Delhi 110076, India. Email: paritoshjha32@gmail.com

CITE THIS RESEARCH AS Jha P, Bhinde S, Rudrappa HC, Ruknuddin G, Prajapati PK. Macro-microscopic Differentiation of Guduchi Satva Samples Collected from Market. J Ayu Med Sci 2018;3(4):451-5.

DOI 10.5530/jams.2018.3.28

\section{Guduchi satva (aqueous extract of Tinospora}

cordifolia) is time tested and widely used medicine in Ayurveda prescriptions. Satva or Sara of herbs is the essence or active part and here it refers to the water extractable solid substance collected from herbal drug. ${ }^{[1]}$ It can be considered as a secondary derivative of Hima kalpana (cold infusion) because a part of pharmaceutical process involved in it is analogous to Hima kalpana. Among all herbal Satvas, Guduchi satva is widely used formulation in Indian Systems of Medicine. Foremost citation of Guduchi satva is available in Rasendra Mangalam. ${ }^{[2]}$ Its pharmaceutical process is mentioned in Yoga Ratnakara, ${ }^{[3]}$ Rasa Yoga Sagara ${ }^{[4]}$ and Siddha Yoga Sangraha. ${ }^{[5]}$
Classics have mentioned that a drug is most suitable for the person if it is cultivated or collected from their local areas; should be collected during seasons mentioned for the collection of particular part of drug; standard methods of preparations for almost every drug; and shelf-life of various forms of medicines. If one follows all above rules, chances of variation in final product can be possibly minimized.

India is providential to have vast knowledge of traditional herbal medicine. Although, during the past 20 years, herbal products have enjoyed resurgence among consumers throughout the world, one of the obstacles in their acceptance is the lack of uniform standard manufacturing protocols (SMPs). Maintaining the identical SMPs is an important step in the 
process of wide spread acceptance of herbal drugs. Change in chemical constituent level even creates confusion in pharmacological activity of its organic constituents.

Guduchi satva is prepared as per classical methods by cutting and crushing fresh stems of $T$. cordifolia followed by soaking in six times of water for eight hours. It is properly macerated and filtered through cotton cloth. The filtrate is placed undisturbed to allow the starch to settle down, supernatant liquid is decanted and the sediment is further collected and dried. This is considered as laboratory sample of Guduchi satva. Besides, four market samples of Guduchi satva were collected from different parts of country and efforts have been made to check organoleptic and microscopic characterization of the samples.

All samples showed whitish tint, but still there is variation in color between each sample. In Rasa Yoga Sagara, the color of Satva is mentioned as Subhrakhandanibha (clear white like sugar cubes) and Yoga Ratnakara explains it as Sankhanibha (clear white like conch shell). Recent texts mention it as greenish white or grayish white ${ }^{[6]}$ in color. These indicate that change in color could be acceptable if it is prepared with different references.

There is difference in taste between all five samples starting from 'tasteless' to 'moderately bitter'. This type of variation in Satva may raise questions on authenticity of pharmaceutical processes adopted by respective pharmacies. For any Ayurvedic drug, Rasa (taste) is most important for the initiation of its action. Touch of all five samples is fine, which must be there for every Satva preparation (Table 1).

Almost all samples have simple starch gains. This indicates that Satva process helps to bring out starch grains of that particular drug. So the drug which has its active principles in starch should be used to get Satva. Slight variation in micro measurements is seen between all samples (Table 2). This could be due to difference in quality of raw material. India having vast diversity in climatic condition and hence change in quality and quantity of active principals are inevitable and hence slight variation in final product could be acceptable. Not only area but season also affects the potency of formulation and to minimize the changes and maximize the potency.

Table 1. Organoleptic characters of various Guduchi satva samples

\begin{tabular}{llllll}
\hline Organoleptic parameters & Sample 1 & Sample 2 & Sample 3 & Sample 4 & Sample 5 \\
\hline Color & Dull white & Whitish-grey & Dull white & Whitish-grey & Off white \\
Odour & Characteristic & Characteristic & Characteristic & Characteristic & Characteristic \\
Taste & Moderately Bitter & Bitter & Tasteless & Bitter & Slightly bitter \\
Touch & Fine & Fine & Fine & Fine & Fine \\
\hline
\end{tabular}

Table 2. Microscopic characters of various Guduchi satva samples

\begin{tabular}{llllll}
\hline Characters & Sample 1 & Sample 2 & Sample 3 & Sample 4 & Sample 5 \\
\hline Starch & Simple, rounded to & Simple, rounded to oval & Simple, rarely with & Simple, rarely & Simple, plenty of \\
grains & oval in shape, rarely & in shape with clumps, & hilum, More mass & with hilum, & rounded to oval grains, \\
& with hilum, more & rarely with hilum, more & of angular grains & angular grains & rarely with hilum, \\
& angular grains. & angular grains. & & & angular grains rare \\
Size in $\mu \mathrm{m}$ & $20 \times 60$ to $40 \times 80$ & $30 \times 60$ to $40 \times 60$ & $20 \times 30$ to $30 \times 50$ & $20 \times 50$ to $40 \times 50$ & $20 \times 50$ to $30 \times 60$ \\
Inference & Prepared afresh from 60 Prepared afresh from & May be adulterated & Prepared some & Prepared afresh from \\
& matured and young & matured and young stem & with rice floor or & time ago from & matured and young \\
& stem collection & collection & Ipac & matured stem & stem collection
\end{tabular}


Figure 1. Macro-microscopic feature of Guduchi satva sample 1
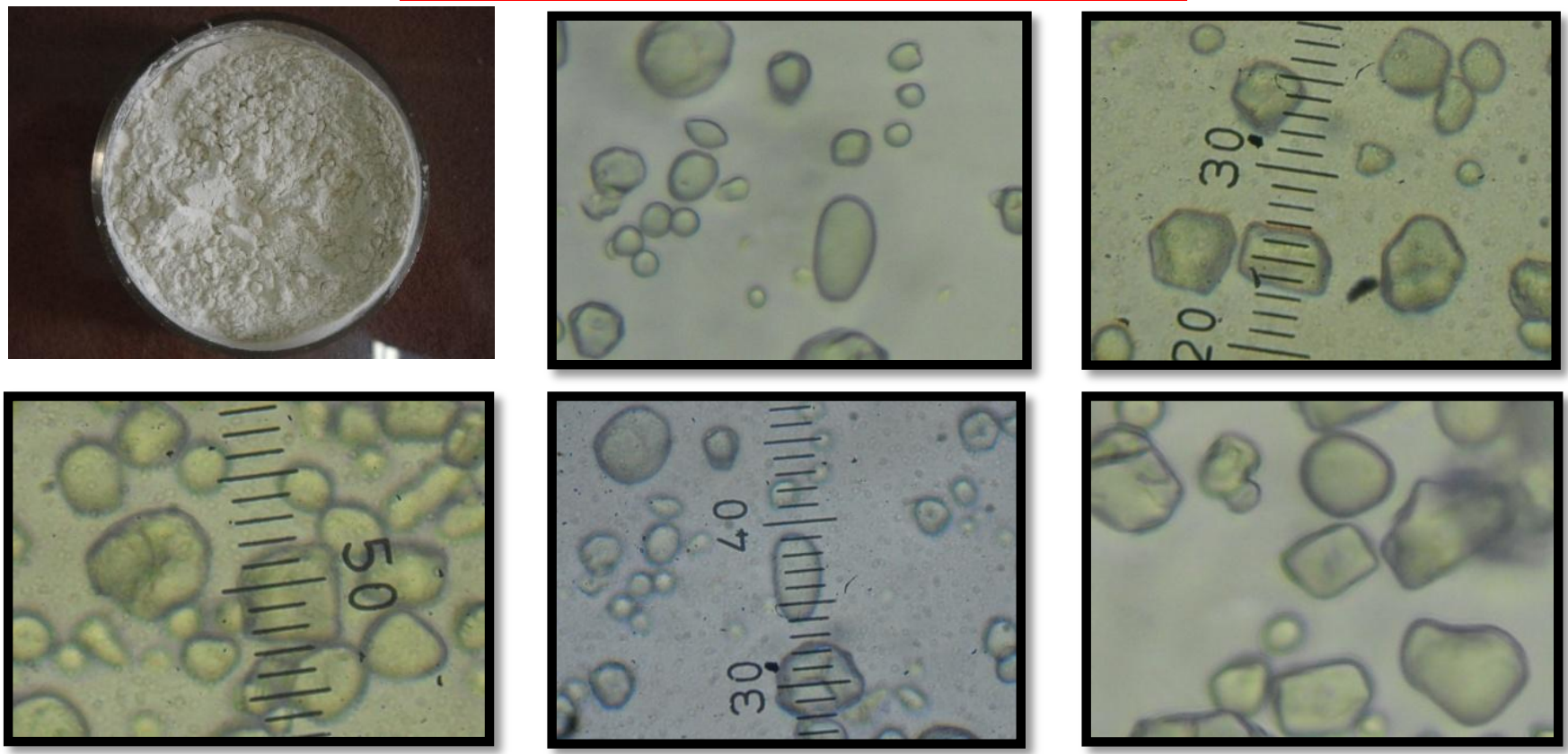

Figure 2. Macro-microscopic feature of Guduchi satva sample 2
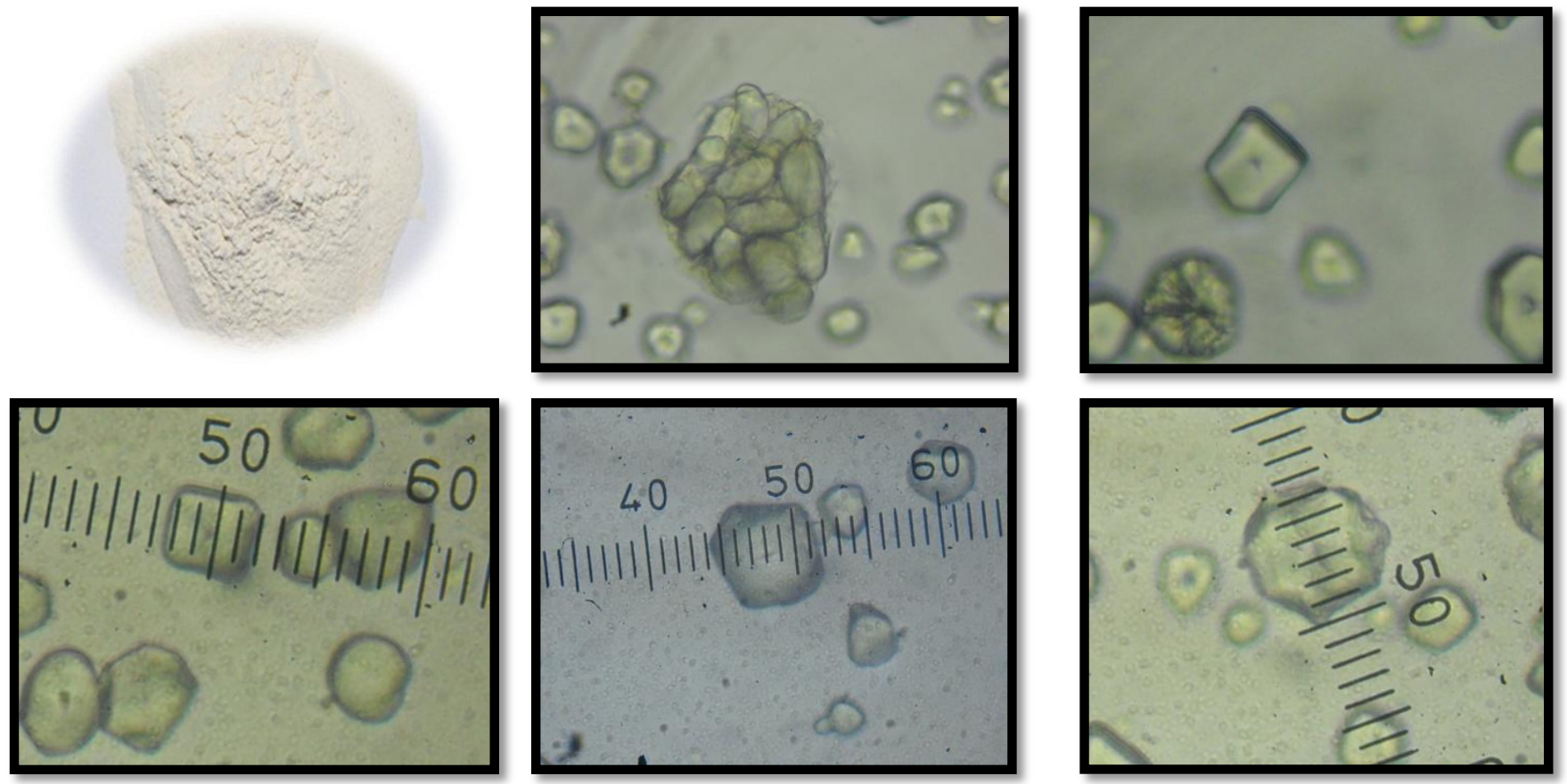

Figure 3. Macro-microscopic feature of Guduchi satva sample 3
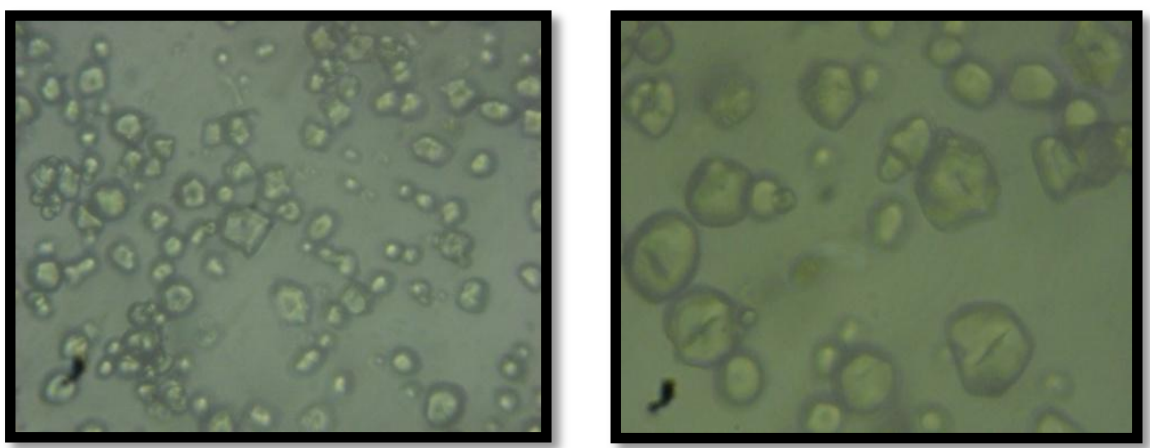

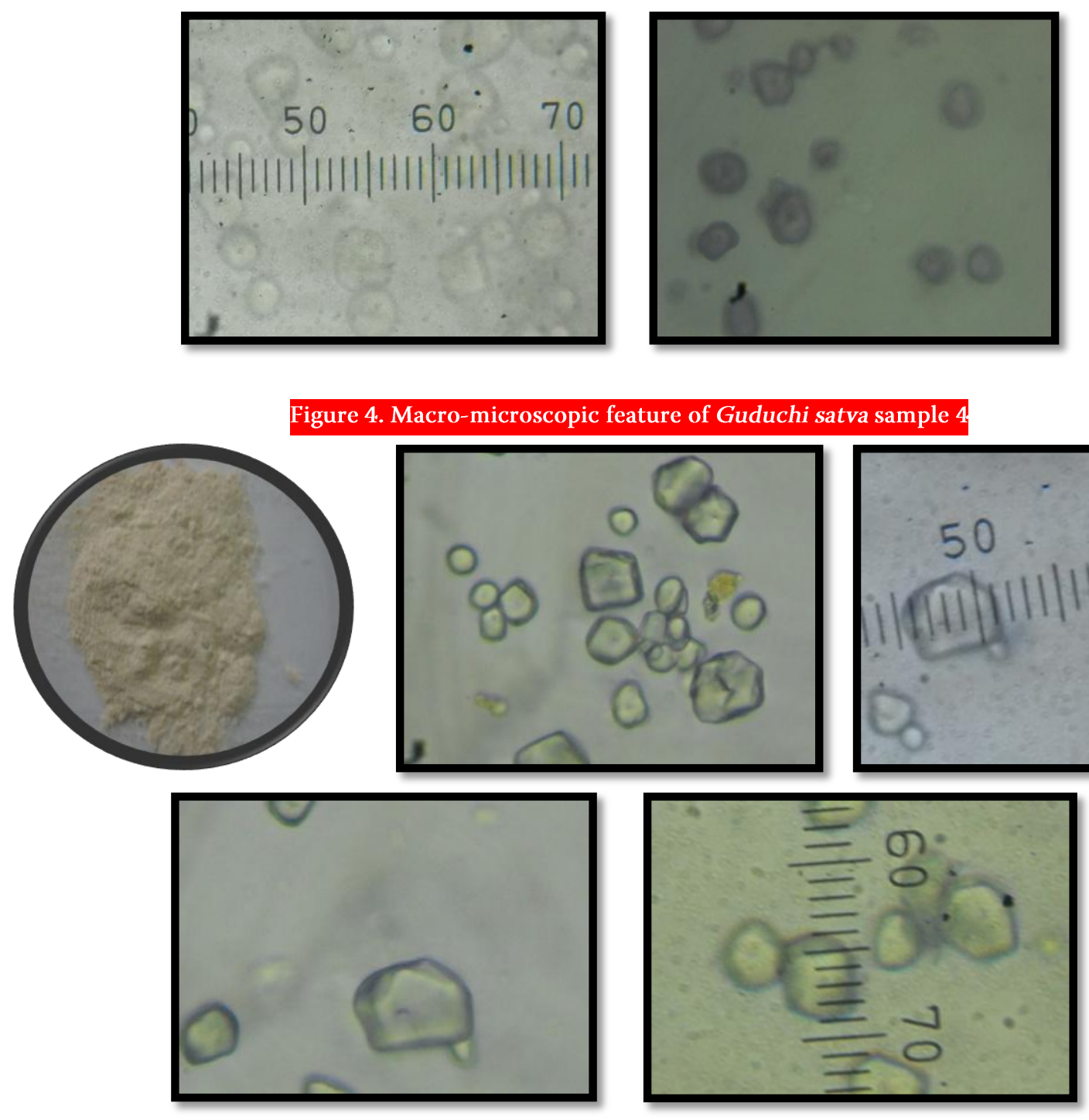

Figure 5. Macro-microscopic feature of Guduchi satva sample 5
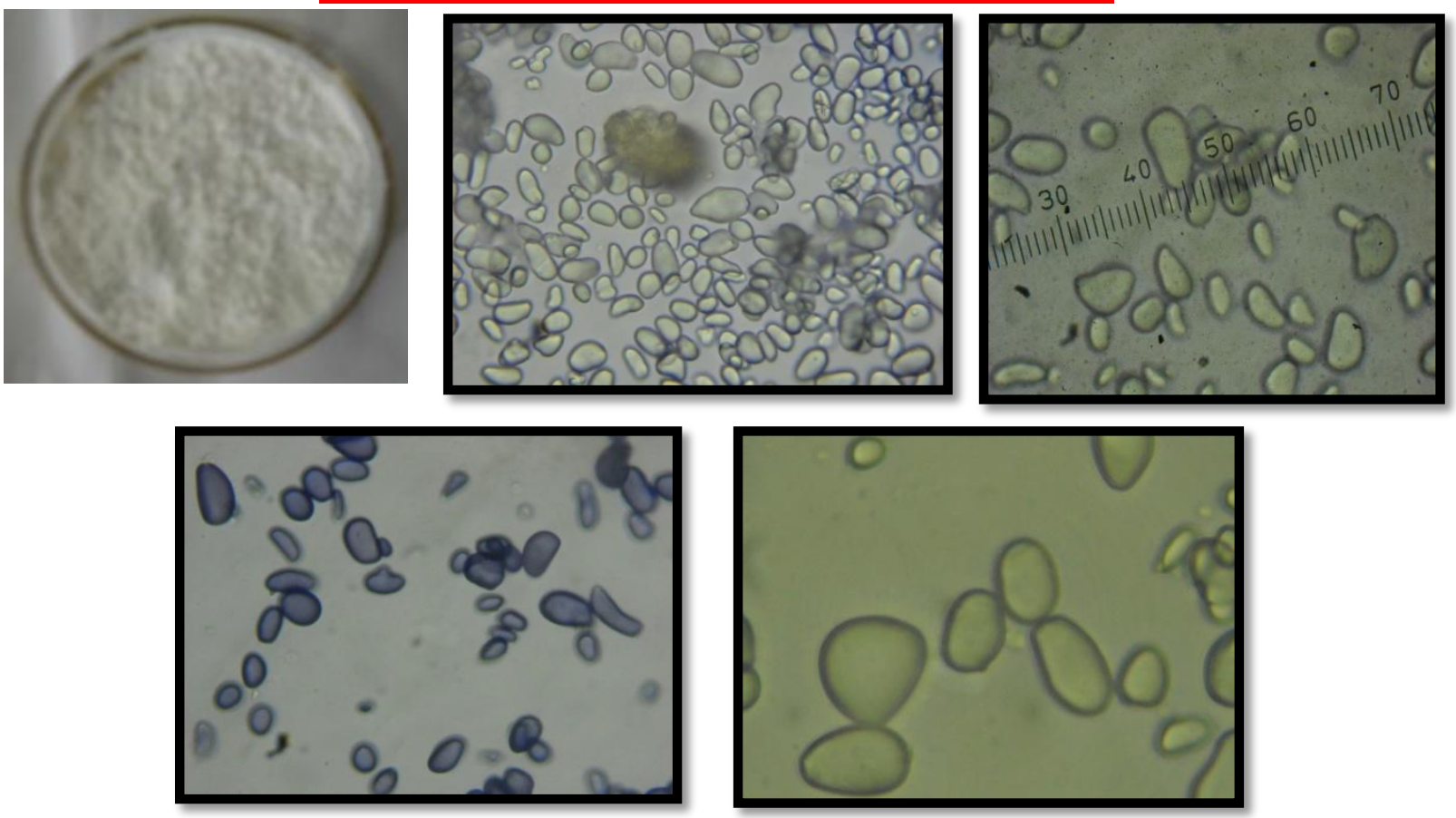


\section{CONCLUSION}

The work has shown variations in Guduchi satva of randomly selected pharmacy samples and one lab sample. Reason behind this may be due to collection of raw material from different seasonal and climatic conditions, differences in adapted method of preparation etc. This research confirms that even though Guduchi satva is widely used in practice, authentic and approved SMP is lacking among manufacturers, hence posing a challenge to establish an acceptable processing method. This work shows that pharmaceutical companies may not be following same reference for drug preparation or fails to maintain one or more basic rules of Ayurveda pharmaceutics. Solution for this could be made by making consensus by all pharmaceutical companies for the use of identical classical reference in formulation preparations. Monographs in AFI and API could be the answer for this.

\section{SOURCE OF SUPPORT Nil}

CONFLICT OF INTEREST The authors declare no conflict of interest.
CONTRIBUTORS Dr. Paritosh Jha contributed in preparation of the laboratory sample and collection of Pharmacy samples. Dr Sonam Bhinde contributed in literature study and data acquisition. Dr. Prajapati PK contributed to the conceptualization of the topic. Dr Harisha CR and Dr. Galib contributed to the manuscript review, analysis, design and literature study.

\section{REFERENCES}

1. Ayurvedic Formulary of India, part-1, $2^{\text {nd }}$ ed. New Delhi: Controller of Publications, Ministry of Health and Family Welfare, Govt. of India; 2003; p.560.

2. Sharma HS, editor. Rasendra Mangalam of Nagarjuna. Chapter 3, Verse 112. Varanasi: ChoukhambaOrientalia, 2008; p.84.

3. Shastri B, editor. Commentary Vidhyotani of Shastri L on Yogaratnakara of Anonymous; 7th ed. Varanasi: Choukhamba Sanskrit Sansthan, 2002; p. 118.

4. Sharma H, editor. Rasa Yoga Sagara. Reprint ed. Varanasi Chaukhamba Krishnadas Academy, 2004; p.378.

5. Acharya YJT. Siddha Yoga Sangraha, Jwaradhikara, chapter 14, $13^{\text {th }}$ ed. Nagpur: Baidyanath Ayurveda Bhavan Ltd, 2008; p.83-4.

6. Hiremath SG. A Text Book BhaishajyaKalpana. $2^{\text {nd }}$ revised ed. Part 1, Chapter 19. Varanasi: Chaukhamba Orientalia, 2005; p.220. 